\title{
Experimental validation of a numerical model for the strand shape in material extrusion additive manufacturing
}

Serdeczny, Marcin P.; Comminal, Raphaël Benjamin; Pedersen, David B.; Spangenberg, Jon

Published in:

Additive Manufacturing

Link to article, DOI:

10.1016/j.addma.2018.09.022

Publication date:

2018

Document Version

Peer reviewed version

Link back to DTU Orbit

Citation $(A P A)$ :

Serdeczny, M. P., Comminal, R. B., Pedersen, D. B., \& Spangenberg, J. (2018). Experimental validation of a numerical model for the strand shape in material extrusion additive manufacturing. Additive Manufacturing, 24, 145-153. https://doi.org/10.1016/j.addma.2018.09.022

\section{General rights}

Copyright and moral rights for the publications made accessible in the public portal are retained by the authors and/or other copyright owners and it is a condition of accessing publications that users recognise and abide by the legal requirements associated with these rights.

- Users may download and print one copy of any publication from the public portal for the purpose of private study or research.

- You may not further distribute the material or use it for any profit-making activity or commercial gain

- You may freely distribute the URL identifying the publication in the public portal 


\section{Accepted Manuscript}

Title: Experimental validation of a numerical model for the strand shape in material extrusion additive manufacturing

Authors: Marcin P. Serdeczny, Raphaël Comminal, David B. Pedersen, Jon Spangenberg

PII: $\quad$ S2214-8604(18)30458-5

DOI: $\quad$ https://doi.org/10.1016/j.addma.2018.09.022

Reference: $\quad$ ADDMA 511

To appear in:

Received date: $\quad 28-6-2018$

Revised date: $\quad 17-9-2018$

Accepted date: $\quad 18-9-2018$

Please cite this article as: Serdeczny MP, Comminal R, Pedersen DB, Spangenberg J, Experimental validation of a numerical model for the strand shape in material extrusion additive manufacturing, Additive Manufacturing (2018), https://doi.org/10.1016/j.addma.2018.09.022

This is a PDF file of an unedited manuscript that has been accepted for publication. As a service to our customers we are providing this early version of the manuscript. The manuscript will undergo copyediting, typesetting, and review of the resulting proof before it is published in its final form. Please note that during the production process errors may be discovered which could affect the content, and all legal disclaimers that apply to the journal pertain. 


\title{
Experimental validation of a numerical model for the strand shape in material extrusion additive manufacturing
}

Marcin P. Serdeczny, Raphaël Comminal, David B. Pedersen, Jon Spangenberg

Department of Mechanical Engineering, Technical University of Denmark, Kgs. Lyngby, Denmark

Intended journal of submission: Additive Manufacturing (Elsevier).

\begin{abstract}
We investigate experimentally and numerically the influence of the processing conditions on the cross-section of a strand printed by material extrusion additive manufacturing. The parts manufactured by this method generally suffer from a poor surface finish and a low dimensional accuracy, coming from the lack of control over the shape of the printed strands. Using optical microscopy, we have measured the cross-sections of the extruded strands, for different layer heights and printing speeds. Depending on the processing conditions, the cross-section of the strand can vary from being almost circular to an elongated rectangular shape with rounded edges. For the first time, we have compared the measurements of strands' cross-sections to the numerical results of a three-dimensional computational fluid dynamics model of the deposition flow. The proposed numerical model shows good agreement with the experimental results and is able to capture the changes of the strand morphology observed for the different processing conditions.
\end{abstract}

Keywords: Material extrusion additive manufacturing; Fused filament fabrication; Strand cross-section; Numerical simulations; Experimental validation.

\section{Introduction}

In material extrusion Additive Manufacturing ( $A M)$, also known as fused filament fabrication or fused deposition modeling, a semi-liquid material is extruded through a nozzle and selectively deposited in the form of a strand, to create the layers of a sliced three-dimensional object. The parts manufactured by material extrusion AM used to be primarily employed for prototyping and rapid tooling; however, their areas of application as finished components have broadened every year as the process more frequently meet the stringent requirements to deliver end-use products [1, 2]. The most common material extrusion AM machines use thermoplastics, where the feedstock is a solid filament fed into a liquefier that melts the material before the extrusion [3]. The extruded strands bond to the previously deposited material by the mean of a temperature-driven diffusion process [4].

The material extrusion AM process is often more economical than other AM techniques [3] and easier to use as the popular build materials are non-toxic [5]. AM technologies are especially attractive in applications with low volumes of production and complex geometries, e.g. unmanned aerial vehicles [6]. However, the components produced by material extrusion AM have anisotropic mechanical properties that are affected by the build orientation of the part [7] and the tool path calculated by the slicing software. The mechanical properties of the components can be improved by using a feedstock material reinforced with fibers and metallic/ceramics particles $[8,9,10]$. Another inherent feature of the layered-based manufacturing methods is that the finished parts have rough surfaces, which are more difficult to post-process in the case of thermoplastics than for metals [3]. Therefore, the processing conditions must be well controlled for an optimal rendering of the surfaces $[11,12,13]$.

The fabrication time and the manufacturing resolution depend on the size and the shape of the extruded strands, which relate themselves to the processing conditions. The strand shape was idealized with mathematical expressions in [11, 14] in order to predict the dimensional accuracy and the surface roughness of the parts. The cross-section of the strand is also an important parameter for the bonding strength between the layers, as it determines the width of the bonding area $[4,15,16]$. Moreover, the 
strand profile affects the cooling rate of the part via heat conduction between the adjacent strands and layers [17, 18, 19]. Furthermore, knowledge about the strand shape allows better control of the part porosity [15] and its mechanical properties [7, 20]. A literature review on the statistical relations between the extrusion conditions and the properties of the final parts was made in [21]. It was found that the mechanical properties are strongly correlated to the layer thickness [17, 22], the build orientation $[17,7,23,24]$, and the infill density of the parts $[17,25,26]$. The surface roughness is significantly influenced by the layer thickness [27] and the build orientation [28].

Numerical modelling has been widely used to acquire knowledge about processes [29], for example in ceramics tape casting [30, $31]$, or in the production of sand molds [32, 33], to cite a few. In the field of material extrusion AM, numerical models have been developed to simulate the temperature distribution and the cooling rate of the extruded material [34, 35, 36, 18, 37]. Some of the thermal models have also been coupled to thermomechanical finite-element analysis to predict the deformation of the part due to the development of thermal stresses [38, 39], and the locations of crack initiation [40]. Numerical models have also been developed to predict the crystallization of semi-crystalline polymers during material extrusion additive manufacturing [41, 42]. Bellini conducted a comprehensive numerical study of the deposition of ceramic pastes using two-dimensional numerical simulations [43]. The pressure drop inside the liquefier was investigated using Computational Fluid Dynamics (CFD) simulations $[44,45,46]$. A three-dimensional computational thermo-fluid dynamics simulation of the material deposition was performed by Dabiri et al. [47] and the model was extended in [48] to include a shear- and temperature-dependent viscosity function of the polymer melt. In [49], the research was further expanded to simulate the thermal expansion of the material, the development of the thermal stresses, and the physical presence of the extrusion nozzle. Du et al. [50] also presented a thermo-fluid numerical model of the polymer melt deposition in laser-assisted material extrusion AM. Their focus was on the improvement of the bonding quality between the strands, resulting from the heat source of a laser. Heller et al. [51] proposed a CFD numerical model to predict the effects of the nozzle geometry and the extrudate swell on the fiber orientation within a fiber-reinforced polymeric feedstock. The deformation and relaxation of the polymer chains during the material deposition was investigated by Mcllroy and Olmsted [52], who assumed that the deposited strand has an elliptic cross-section. Comminal et al. [53] developed a simplified twodimensional isothermal model of the deposition flow. The viscoelastic effects of the polymer melt were included in the twodimensional thermo-fluid model of Liu et al. [54], developed in OpenFOAM, to investigate the impact of the printing speed and the external geometry of the nozzle on the deposition flow. A three-dimensional isothermal CFD model of the strand deposition was presented by Comminal et al. [55], who investigated the effects of the printing conditions on the strand shape, under the assumptions of a Newtonian fluid. It was notably found that the strand shape varies significantly with the layer height and the printing speed. This model was further expanded by Serdeczny et al. [56] who included a pseudo-plastic constitutive behavior; however, it was found to have a negligible influence on the strand shape. Despite the recent interest in the modeling of the deposition flow in material extrusion AM, most of the numerical models lack experimental validation.

In this paper, we use an experimental procedure to validate the predictions of the strand morphology obtained by CFD simulations. We compare the simulated strand cross-sections to experimental measurements, for different printing conditions. The influence of the layer height and the printing speed on the cross-sectional profile of the extruded strand is experimentally verified. The numerical model simulates an isothermal deposition flow of a Newtonian fluid and reveals the first-order effects of the influence of printing conditions on the strand morphology. An overview of the experimental setup and the numerical model is given in Section 2. The numerical predictions and the experimental measurements of the strand cross sections are quantitatively compared in Section 3. We conclude and summarize the results of our study in Section 4.

\section{Methodology}

\subsection{Experimental measurements}

The experiments were conducted using an open-source desktop 3D-printer (BQ Hephestos 2) with a nozzle diameter of 0.4 mm, see Figure 1. We used a polylactic acid (PLA) feedstock filament and the extrusion temperature of $200{ }^{\circ} \mathrm{C}$. Even though the extrusion temperature has an effect on the viscosity of molten thermoplastics, it was not varied in this study, since a previous numerical study [56] has shown that changes in the dynamic viscosity have neglible impact on the strand shape. The strands were printed directly on a planar substrate that was at room temperature. For the sake of comparison, we investigated the same range of printing conditions as in [55]. The values of the printing parameters are provided in Table 1. All the toolpaths of the printing head were written manually in the G-code. Each printed strand was cut through their cross-sections, perpendicular to the printing direction. The cross-sections were grinded on a rotating machine using an abrasive disk with granulation 4000 and were examined under an optical microscope with a magnification of 200x. The contours of the strands' cross-sections were extracted from the micrographs by image analysis with MATLAB. The measurement accuracy was about $5 \mu$ m. However, the main sources of errors 
in the experiments came from the uncertainty in the positioning of the printing head and in the control of the filament feeding rate. Therefore, we established a calibration procedure to correct systematic errors in the filament feeding rate and in the vertical position of the printing head, as described below.

Table 1. Printing parameters in the experiments.

\begin{tabular}{|c|c|c|c|}
\hline Variable & Symbol & Unit & Value \\
\hline Gap height (nozzle position above the substrate)* & $g$ & $\mathrm{~mm}$ & $0.48,0.40,0.32,0.24,0.16$ \\
\hline Nozzle diameter & $D$ & $\mathrm{~mm}$ & 0.4 \\
\hline Normalized gap height & $g / D$ & - & $1.2,1.0,0.8,0.6,0.4$ \\
\hline Extrusion volumetric flux (average velocity inside the nozzle)* & $U$ & $\mathrm{~mm} / \mathrm{s}$ & 20 \\
\hline Printing head velocity & V & $\mathrm{mm} / \mathrm{s}$ & $20,15,10$ \\
\hline Normalized printing head velocity & $V / U$ & - & $1.0,0.75,0.5$ \\
\hline Extrusion temperature & $T$ & ${ }^{\circ} \mathrm{C}$ & 200 \\
\hline
\end{tabular}

*Values after the calibration procedure

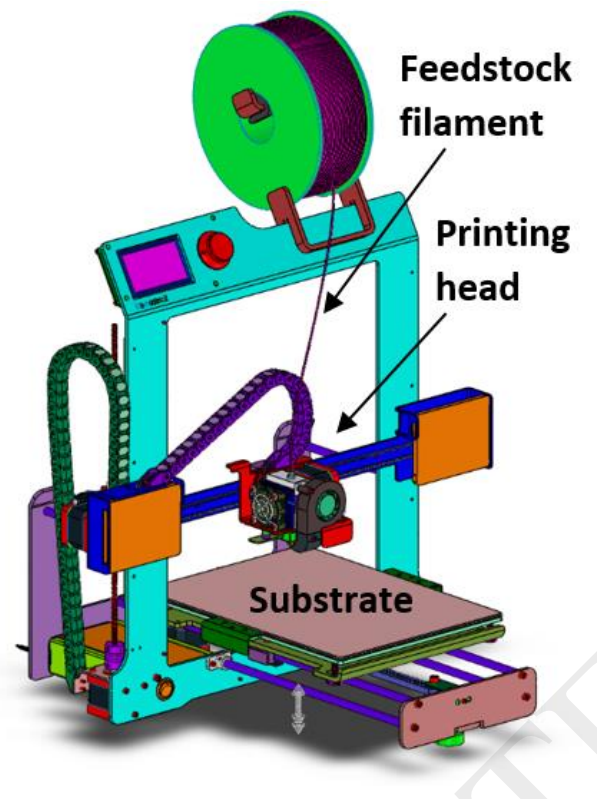

(a)

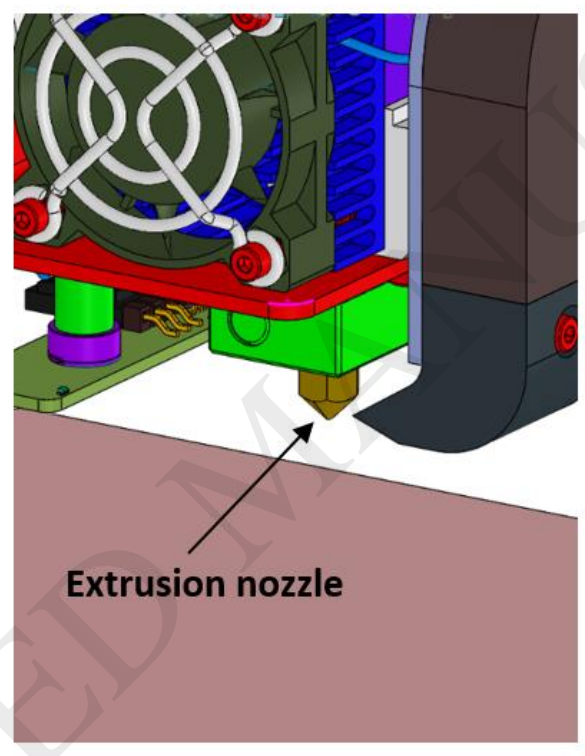

(b)

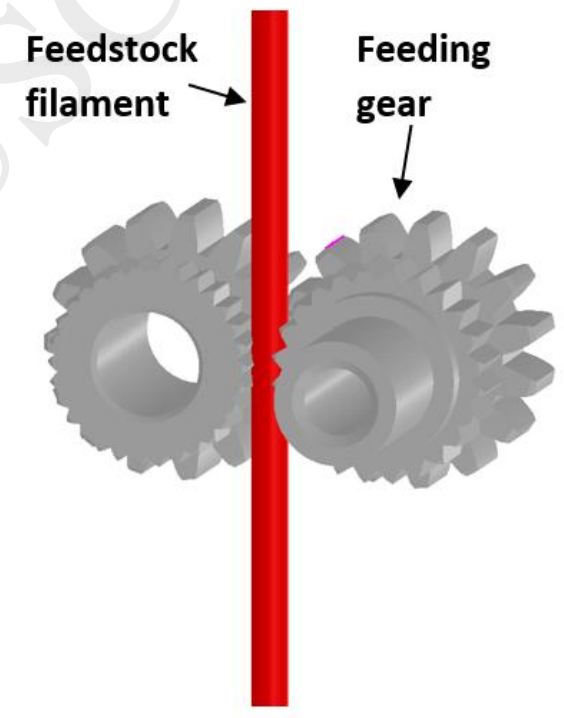

(c)

Figure 1. Assembly model of the BQ Hephestos 2 3D-printer (a), close-up view of the printing head (b), and feeding mechanism of the filament (c). The assembly CAD model is available at [57].

The calibration procedure began with the correction of the filament feeding rate. The nominal values of the filament feeding rate set in the G-code were adjusted to obtain the desired cross-sectional areas of the strand. The filament feeding rate $V_{f}$ relates to the extrusion volumetric flux $U$ (i.e. the average velocity inside the nozzle) as:

$$
U \frac{\pi D^{2}}{4}=C_{f} \cdot V_{f} \frac{\pi D_{f}^{2}}{4}
$$

where $D$ and $D_{f}$ are the internal diameter of the nozzle and the diameter of the feeding filament, respectively; and $C_{f}$ is a calibration factor that we wished to determine. The calibration factor amends the volume conservation to compensate for the lumped effect of the thermal expansion inside the nozzle, as well as other sources of errors in the filament feeding rate, due to the uncertainty in the effective radius of the feeding gears (see Figure 1c), and the possible slippage of filament [58]. Furthermore, the nominal area of the strand cross-section $A$ relates to the extrusion volumetric flux and the printing head velocity $V$ as

$$
V A=U \frac{\pi D^{2}}{4}
$$


The comparison of the measured cross-sectional areas of printed strands with the expected nominal values yielded a calibration factor that varied from 1.01 to 1.33 . The average value was 1.18 for all the printing conditions, and it was used in all the subsequent extrusions.

In the second stage of the calibration procedure, the vertical position of the printing head was corrected. For that purpose, a single strand was printed with a varying gap height between the nozzle and a stationary substrate, as depicted in Figure 2 . The printing head was moving along a straight line with a constant velocity $V=15 \mathrm{~mm} / \mathrm{s}$, while continuously descending towards the substrate. The gap height was set in the G-code to vary from 2.5D, at the beginning of the strand, to $0.6 \mathrm{D}$, at the end of the strand. The strand was printed along a total length of $190 \mathrm{~mm}$, resulting in a very small angle between the trajectory of the printing head and the substrate, such that the material deposition was close to the steady printing conditions. Subsequently, the printed strand was sliced every $10 \mathrm{~mm}$ to examine the cross-sections at different positions, thereby different gap heights. Figure 3 shows the measured strand heights (normalized by the nozzle diameter) versus the position along the strand, together with the uncorrected gap height set in the G-code (also normalized). We notice that the strand height was abnormally low compared to the gap setting. Moreover, the strand height varied with a lower slope along the printing direction than what we would expect from the prescribed gap height. These observations revealed an error in the parallelism of the $X$-axis of the machine with the planar substrate. As a result, we measured a variable offset of the vertical position (Z-axis) of the printing head along the $X$-axis. The offset was corrected at one reference point by adding a constant correction to the prescribed position of the printing head in the G-code. The reference point of the calibration was chosen at the location where the measured strand height $H$ equaled $0.8 D$ because the ratio $g / D=0.8$ corresponded to the middle value of the gap height in our investigations. The value of the offset correction at that reference point is given by the difference between the specified gap height and the measured strand height, as shown in Figure 3. Our experiments did not require further corrections, as all the subsequent measurements of the strand cross-sections were realized at the same reference point. After the calibration, the strands were printed for all the combinations of the gap heights and the printing speeds specified in Table 1. To ensure repeatability of the process, three strands were extruded individually for each printing condition.

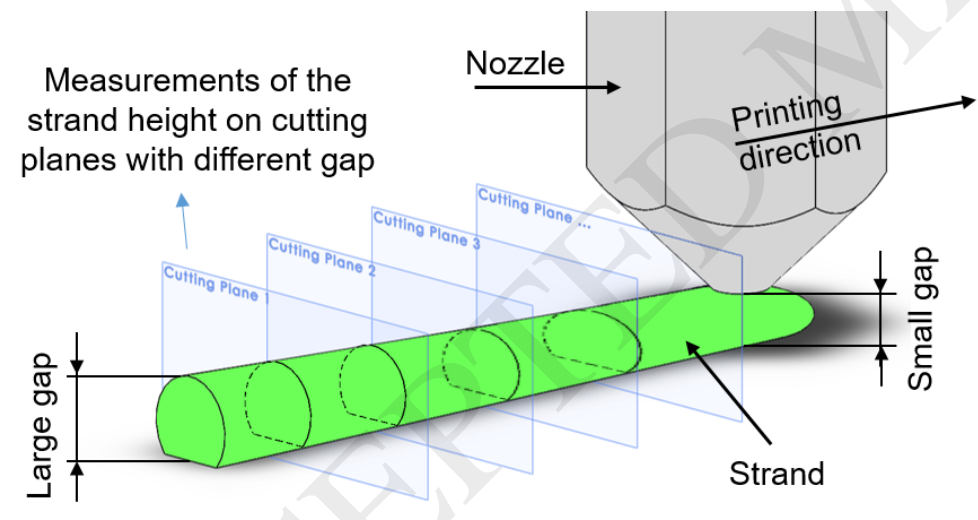

Figure 2. Printing of a strand with a varying gap height for the calibration of the vertical position of the printing head.

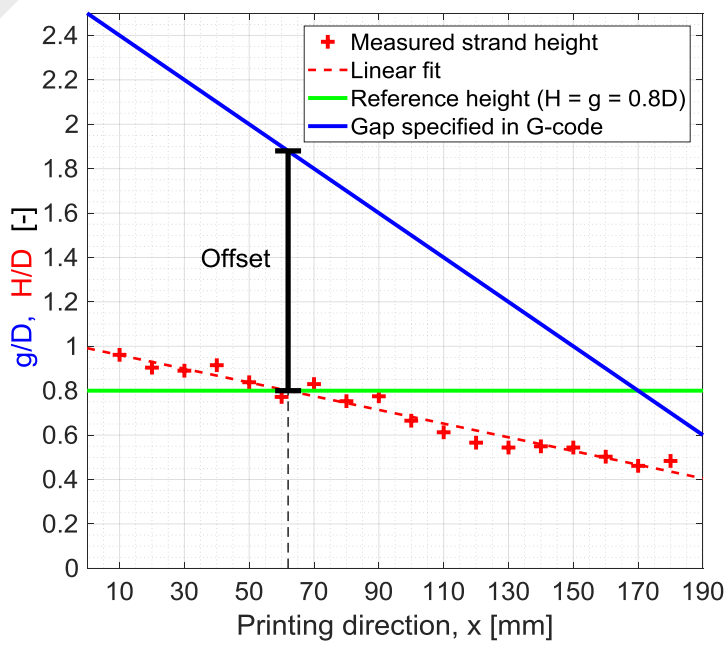

Figure 3. Measured normalized strand heights in the different cutting planes, and uncorrected normalized gap height specified along the printing direction.

\subsection{Numerical simulations}

The CFD model used in this paper is based on the previous work of Comminal et al. [55]. The material deposition was simulated with the CFD software ANSYS ${ }^{\circledR}$ Fluent R18.2 [59]. The numerical model simulated the flow of a molten material in the region between the nozzle and substrate. For simplicity, we modelled the extrusion nozzle as a cylinder with diameter $D$ (see Figure 4), which is slightly different than in the experiment (see Figure $1 \mathrm{~b}$ ). The nozzle was kept stationary while the substrate moved with the constant velocity $V$. In a steady extrusion, the two opposite configurations, where the nozzle moves and the substrate is fixed, and vice versa, are equivalent. The vertical gap between the nozzle orifice and the planar substrate was denoted $g$ and can be also understood as the layer height. Only half of the physical domain was simulated, as the flow was symmetrical with respect to 
the plane cutting through the middle of the nozzle in the direction of printing. A no-slip boundary condition was applied on the substrate and at the walls of the nozzle. All the remaining boundaries of the model were prescribed outlet boundary conditions, where the material was free to exit. As the model focuses on capturing the first order effects of the deposition flow conditions (the gap height and the velocity ratio) on the strand shape, we have simplified the physics with the following assumptions:

- The deposition flow was considered isothermal, as we assumed that the density dependency on the fluid temperature (e.g. due to thermal shrinkage) has a secondary effect on the strand shape.

- Inertial effects were negligible, which means that the material extrusion was in the creeping flow regime (the Reynolds number was below 1 ). For such flow, the actual values of the density $\rho$ and viscosity $\mu$ did not affect the results of the simulations (they were set to $1000 \mathrm{~kg} / \mathrm{m}^{3}$ and $1000 \mathrm{~Pa} \cdot \mathrm{s}$, respectively; and with those values, the Reynolds number had a magnitude of $10^{-5}$ ).

- We modelled the fluid with a constant viscosity, as a previous numerical study has shown that including the shear thinning behavior in the material extrusion process has no significant influence on the strand cross-sectional shape, in a creeping flow regime [56]. Likewise, the dependency of the dynamic viscosity on the temperature was assumed to have a negligible effect on the strand shape.

Providing these assumptions were fulfilled, the deposition flow was fully determined by the geometrical ratio $g / D$ and the velocity ratio $V / U$ of the model's boundary conditions, where $U$ was the average velocity specified at the inlet of the nozzle (i.e. the extrusion volumetric flux). The geometrical ratio $g / D$ characterized the gap between the extrusion nozzle and the substrate with respect to the nozzle diameter. The velocity ratio $V / U$ characterized the relation of the printing speed to the extrusion volumetric flux. Consequently, the results of the numerical simulations are representative for many of the materials commonly used in material extrusion AM (for instance PLA and ABS). After the extrusion, the material was subjected only to the gravitational force, which was too small to cause any further deformations of the strand shape.

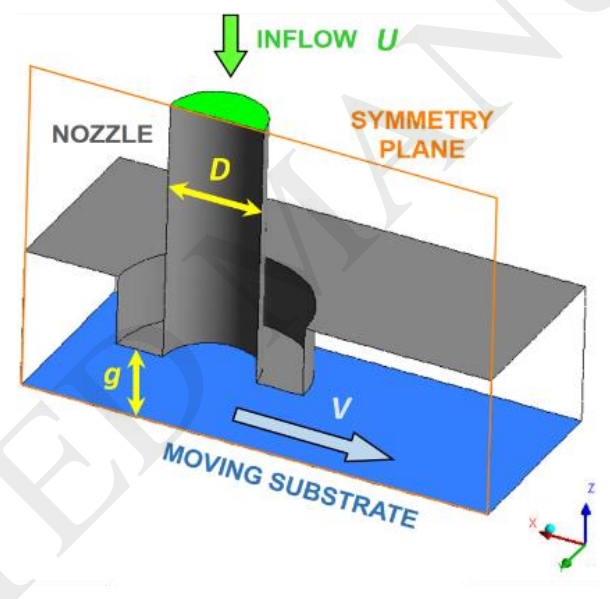

Figure 4. Geometry of the numerical model [55].

The geometry was meshed with tetrahedral elements with a maximum normalized edge length of $\delta I / D=0.03$, which refined the results previously published in [55]. The coupled pressure-velocity solver with the implicit time-marching discretization was chosen to solve the governing equations of the flow (i.e. the conservation of mass and momentum). The free surface of the extruded material was computed with the coupled volume-of-fluid/level-set method. More information about the volume-offluid and the level-set methods can be found in $[60,61,62,63]$. The transient simulations were run until the solutions had reached a steady state. Further details about the numerical model used in this work can be found in [55].

\section{Results and discussions}

In this section, the measured cross-sections of the strands for the different printing conditions are compared with the results of the numerical simulations. Figure 5 represents perspective views of the extruded strand simulated for two different printing conditions. We can see that the numerical simulations predict different morphologies of the deposited strand, depending on the gap height and the extrusion flow rate. Figures 6,7 , and 8 show the cross-sectional shapes of the strands for all the normalized gap heights and the velocity ratios specified in Table 1 . The first column in the figures show the cross-sectional profiles captured at the outlet boundary of the numerical simulations. The next three columns show micrographs of the strand cross-sections, 
measured on three independent extrusions with the same printing conditions. We can see that the experimental observations are repeatable.

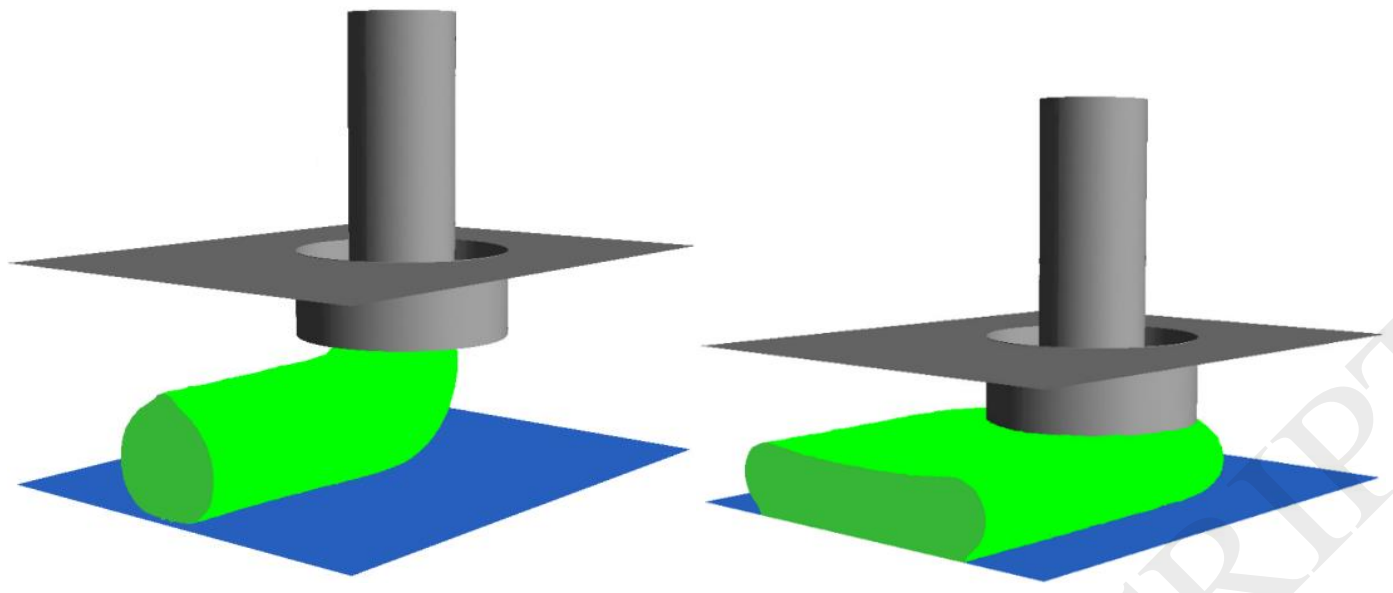

Figure 5. Perspective views of the simulated strand deposition, for a large normalized gap height $g / D=1.2$ and a high velocity ratio $V / U=1$ (left); and a small normalized gap height $g / D=0.6$ at a low velocity ratio $V / U=0.5$ (right). (For the sake of visualization, the simulation domain is mirrored along the symmetry plane.)
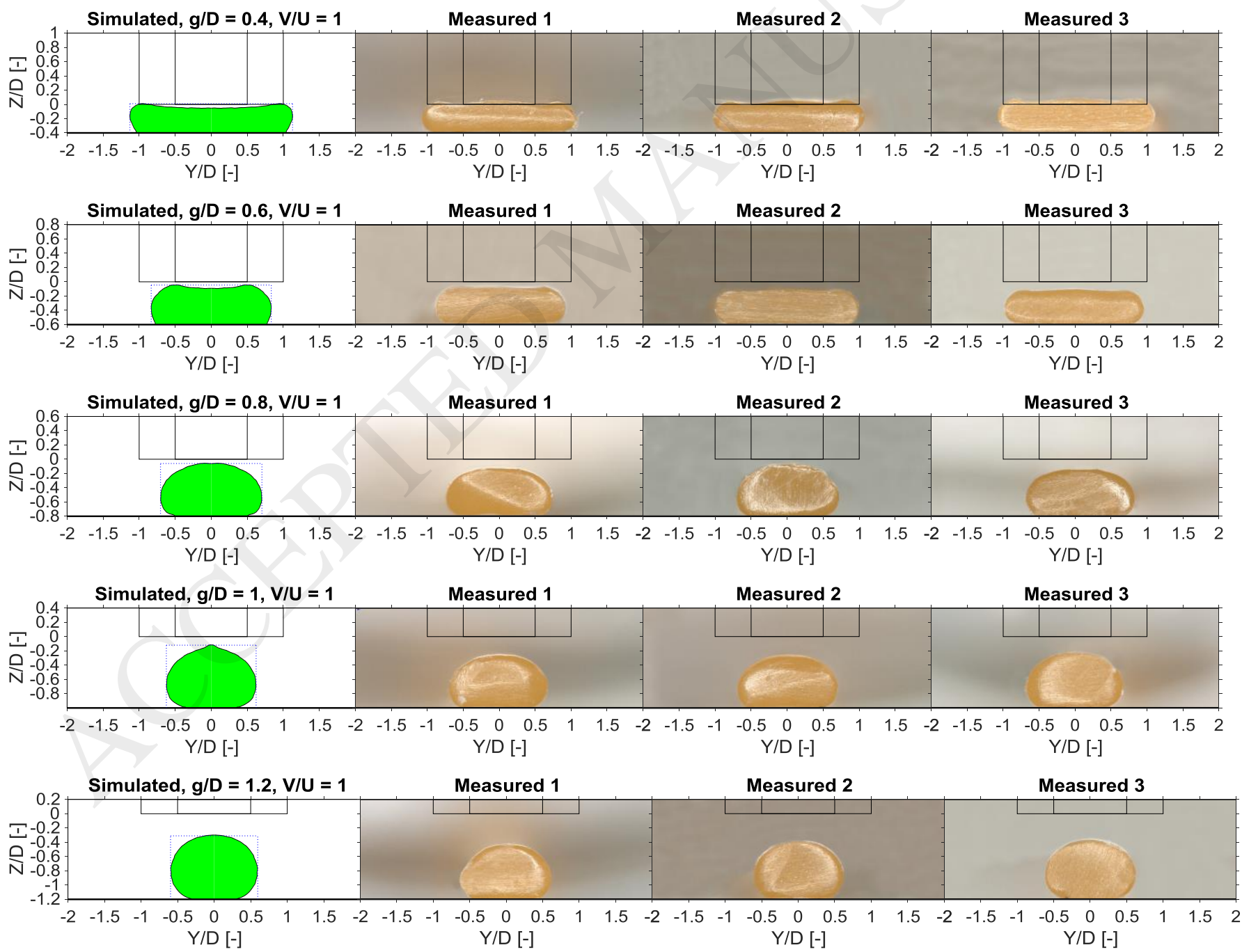

Figure 6. Simulated and measured cross-sectional shapes of the strand for $V / U=1$. The black lines represent the geometry and the position of the extrusion nozzle, behind the observation plane. 
For all the measurements, decreasing the gap height deforms the strand and changes its shape from an oval (for a large gap height), to a flat cuboid with rounded corners (for a small gap height). For the large normalized gap height $(g / D=1.2)$ and the high substrate velocity ratio $(V / U=1)$, the extruded material is not affected by the presence of the nozzle. A slight flattening of the shape is observed, due to the change of the flow direction, from vertical when it leaves the nozzle, to horizontal when it is deposited on the substrate. For $g / D<1$, decreasing the gap height enhances the side flow and forces the extruded strand to change its shape in order to keep a constant cross-sectional area (due to mass conservation). This underlines the fact that, for some process parameters, the approximation of a circular or elliptic strand cross-section may not be accurate, as also suggested in [55]. Decreasing the velocity ratio leads to an increase in the cross-sectional area of the strand as more material is deposited per unit distance of the strand (the extrusion volumetric flux is constant). Generally, the numerical simulations capture well the first order effect of this flattening of the strand due to the change of processing conditions. Slight differences between the simulations and the measurements occur for the very small normalized gap height and the low velocity ratio $(g / D=0.4$ and $V / U$ $\leq 0.75$ ), which is attributed to the differences in the external shape of the nozzle between the simulations and experiment (see Figure $1 \mathrm{~b}$ and Figure 4). The external conic shape of the nozzle (in the experiments) allows more upward flow of the extruded material as compared to the cylindrical nozzle with a flat bottom face (in the numerical model). Nevertheless, this combination of parameters $(g / D=0.4$ and $V / U \leq=0.75$ ) is outside the typical range of the processing parameters used in material extrusion AM.
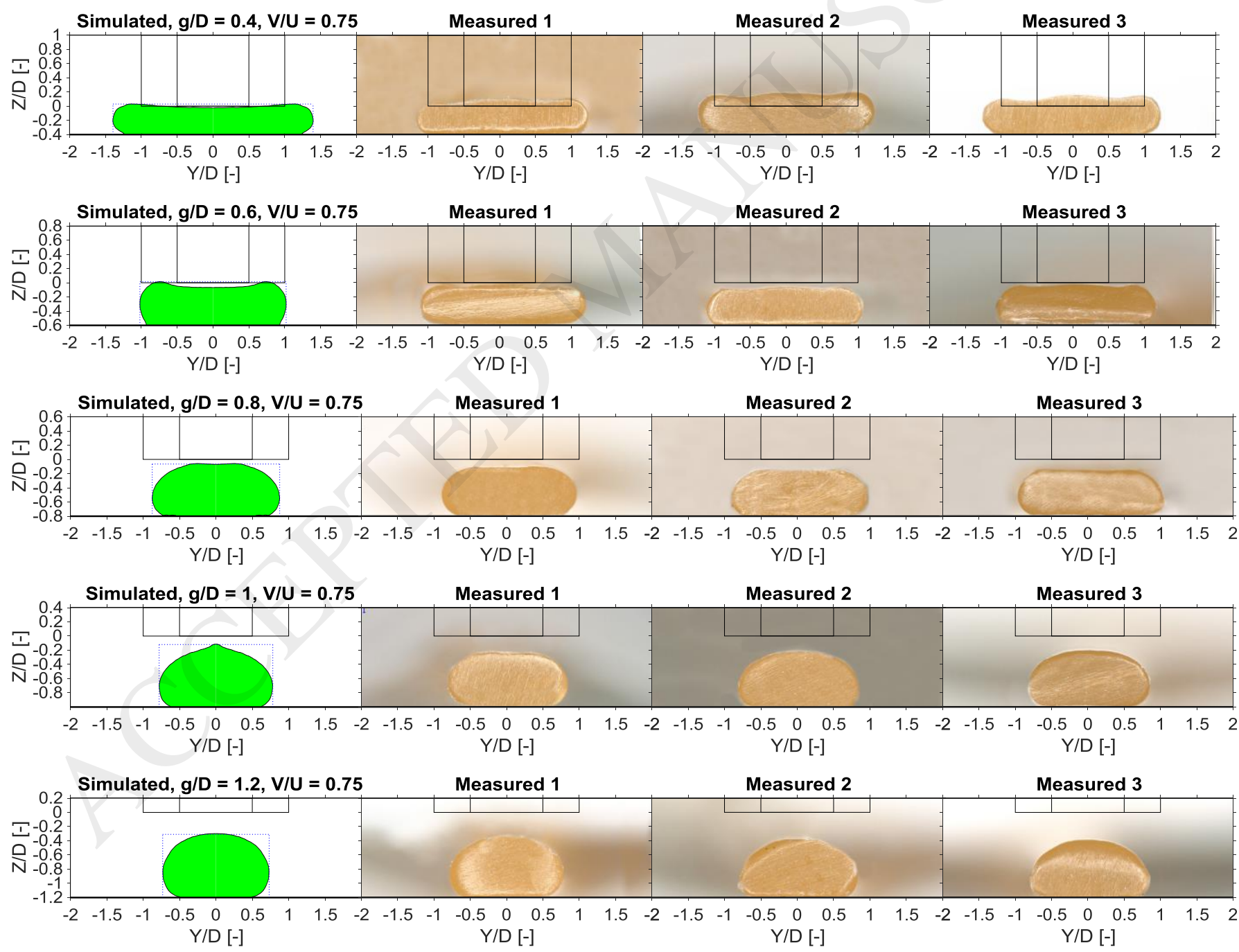

Figure 7. Simulated and measured cross-sectional shapes of the strand for $V / U=0.75$. The black lines represent the geometry and the position of the extrusion nozzle, behind the observation plane. 
The quantitative comparison of the dimensions of the strand cross-sections measured in the experiments and in the simulations is presented in Figure 9. The graphs represent the heights $H$ and widths $W$ of the strands, normalized by the diameter of the nozzle. The influence of the printing conditions (i.e. the ratios $V / U$ and $g / D$ ) on the strand dimensions follows the trends of the numerical predictions. Discrepancies between the simulations and the experiments are mainly observed for the small normalized gap height and the low velocity ratio, as mentioned earlier. The comparison of the aspect ratio $W / H$ and the compactness of the strand cross-sections (defined as the area of the strand cross-section $A$ divided by $W \cdot H$ ) are also represented in Figure 10 . The numerical model provides good predictions of the strand aspect ratio and the compactness in the common range of the gap height, $0.6 \leq g / D \leq 0.8$. A slight discrepancy is observed for the normalized gap height $g / D=1.0$, at the velocity ratios $V / U=1.0$ and $V / U=0.75$. Those deviations come from a small peak on the top of the cross-section shape, seen in the simulations, which is artificially caused by the contact of the extruded material with the bottom surface of the nozzle.

For the sake of comparison, an idealized approximation of the strand cross-section based on the volume conservation is also represented in Figures 9 and 10. The idealized approximation assumes an elliptic cross-section with the strand height equal to the gap height, if the resulting aspect ratio $W / H$ is below 1 , otherwise it assumes a circular cross-section [55]. Overall, it can be seen that the numerical model predicts the strand height and width more accurately than the idealized solution. The simulations give also more accurate predictions of the strand aspect ratio and compactness. Finally, both the simulations and experiments show that for the common velocity ratio, i.e. $V / U=1.0$, the choice of the normalized gap height $g / D=0.6$ is preferable to maximize the compactness of the strand.
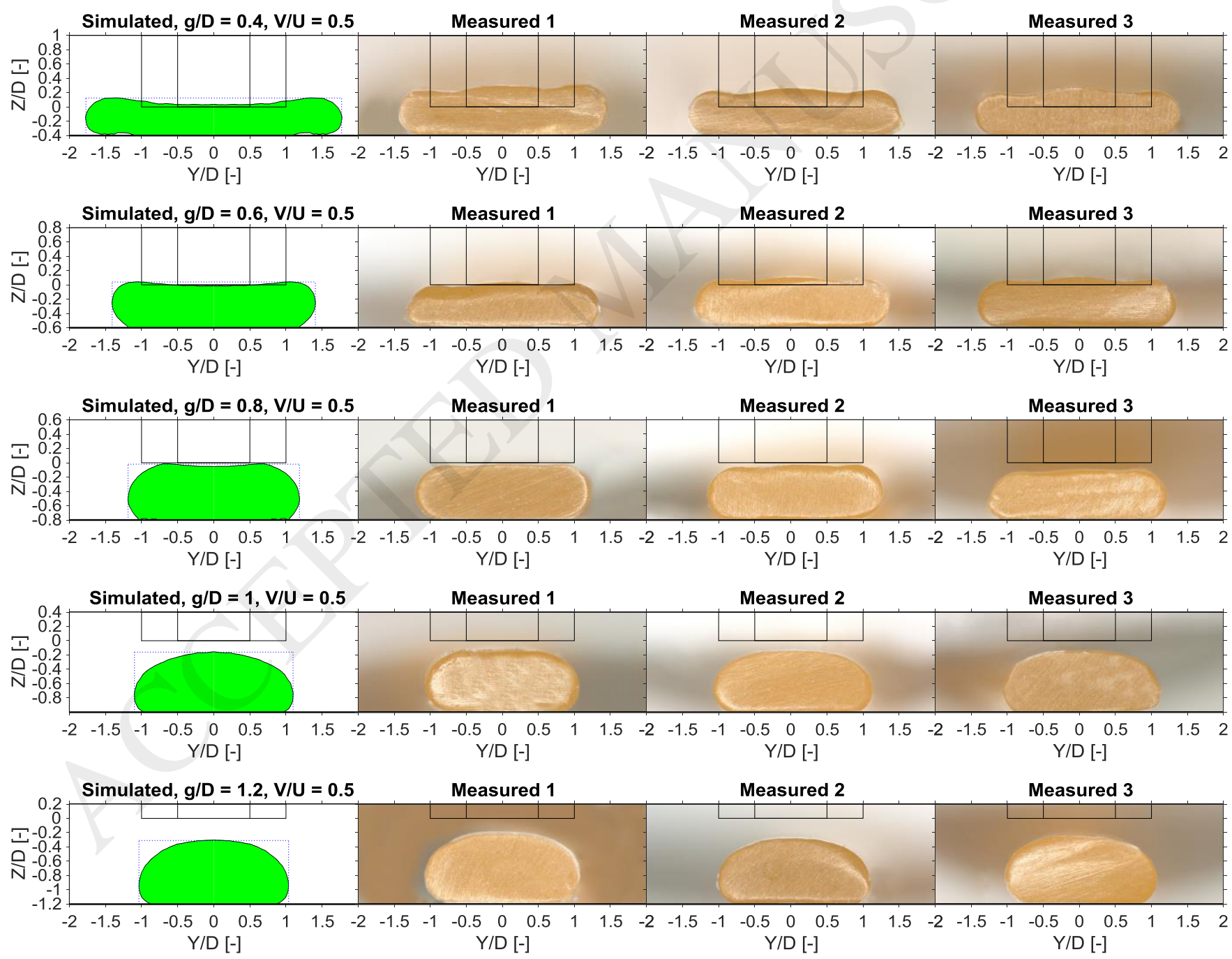

Figure 8. Simulated and measured cross-sectional shapes of the strand for $V / U=0.5$. The black lines represent the geometry and the position of the extrusion nozzle, behind the observation plane. 

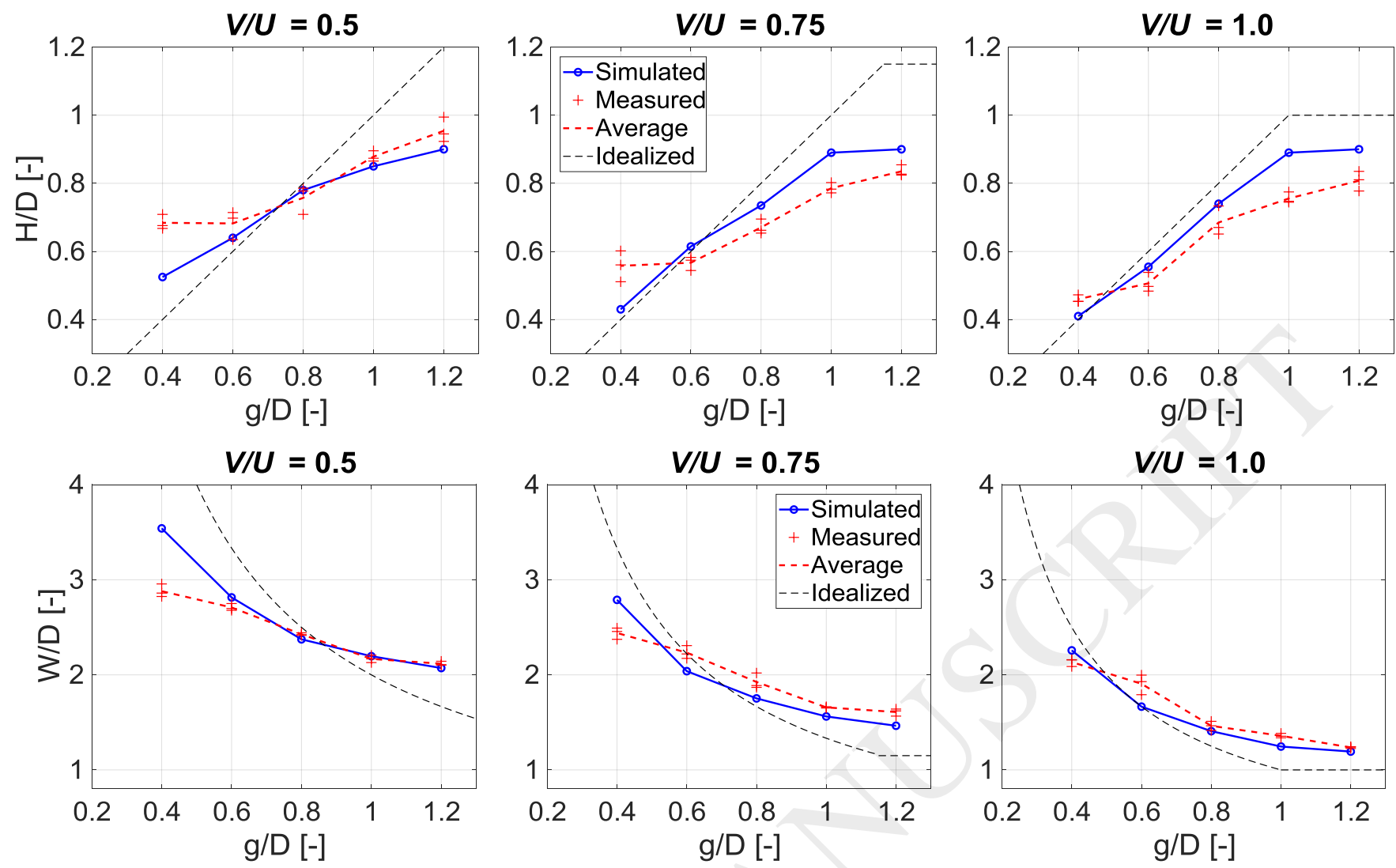

Figure 9. Comparison of the simulated and measured height (top) and width (bottom) of the strand cross-sections.
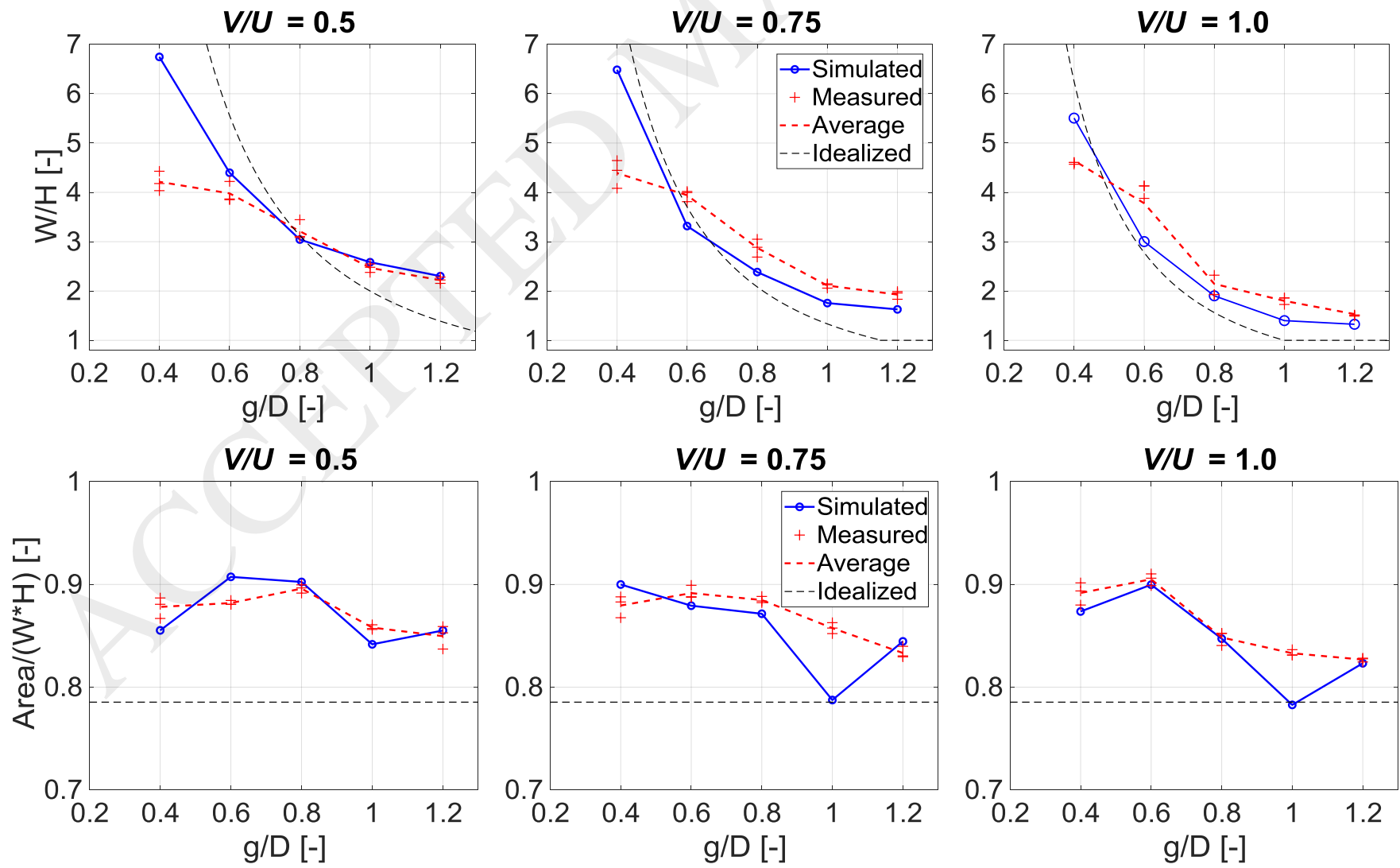

Figure 10. Comparison of the simulated and the measured aspect ratio (top) and compactness (bottom) of the strand crosssections. 


\section{Conclusions}

For the first time, we have validated experimentally a numerical model, which predicts the strand cross-section in material extrusion AM. The 3D printer had to be calibrated for a proper control over the printing conditions during the experiments. The cross-sections of printed strands were measured by optical microscopy. The CFD simulations resolve the three-dimensional flow of the material extruded from the nozzle and deposited on a planar surface. The numerical simulations capture well the changes in the strand shape for the different printing conditions (i.e. the velocity ratio and the normalized gap height), despite the fact that the model does not included the viscoelastic effect and the temperature-dependent material properties of the thermoplastic feedstock. The cross-section of the strand changes from being almost circular to an elongated rectangular shape with rounded edges, when the gap height is reduced or when the velocity ratio is decreased. Slight discrepancies between the measurements and the simulations were found for the very small normalized gap height $(g / D=0.4)$ and the small velocity ratio $(V / U \leq 0.75)$, where the external geometry of the nozzle influences the side flow of the extruded material. However, these printing conditions are very rarely used in practice. On the other hand, in the common window of the process parameters $(0.6<g / D<0.8$ and $V / U=$ 1.0), the numerical model provides better predictions of the strand shape than the idealized elliptical cross-section. Therefore, the proposed CFD model is a good candidate for further developments of high-fidelity numerical simulations of the material deposition in material extrusion AM.

\section{Acknowledgments}

The authors would like to acknowledge the support of the Danish Council for Independent Research (DFF) | Technology and Production Sciences (FTP) (Contract No. 7017-00128).

\section{Declaration of interest: None}




\section{References}

[1] B. N. Turner, S. A. Gold and R. Strong, "A review of melt extrusion additive manufacturing processes: I. Process design and modeling", Rapid Prototyping Journal, vol. 20, no. 3, pp. 192-204, 2014.

[2] B. N. Turner and S. A. Gold, "A review of melt extrusion additive manufacturing processes: II. Materials, dimensional accuracy, and surface roughness", Rapid Prototyping Journal, vol. 21, no. 3, pp. 250-261, 2015.

[3] T. Wohlers, I. Campbell, O. Diegel, J. Kowen and T. Caffrey, "Wohlers Report 2017: 3D Printing and Additive Manufacturing State of the Industry Annual Worldwide Progress Report", Wohlers Associates, 2017.

[4] Q. Sun, G. Rizvi, C. Bellehumeur and P. Gu, "Effect of processing conditions on the bonding quality of FDM polymer filaments", Rapid Prototyping Journal, vol. 14, no. 2, pp. 72-80, 2008.

[5] H. Bikas, P. Stavropoulos and G. Chryssolouris, "Additive manufacturing methods and modelling approaches: a critical review", The International Journal of Advanced Manufacturing Technology, vol. 83, no. 1-4, pp. 389-405, 2016.

[6] G. D. Goh, S. Agarwala, G. L. Goh, V. Dikshit, S. L. Sing and W. Y. Yeong, "Additive manufacturing in unmanned aerial vehicles (UAVs): Challenges and potential", Aerospace Science and Technology, vol. 63, pp. 140-151, 2017.

[7] C. Ziemian, M. Sharma and S. Ziemian, "Anisotropic Mechanical Properties of ABS Parts Fabricated by Fused Deposition Modeling", in Mechanical Engineering, InTech, 2012.

[8] G. D. Goh, V. Dikshit, A. P. Nagalingam, G. L. Goh, S. Agarwala, S. L. Sing, J. Wei and W. Y. Yeong, "Characterization of mechanical properties and fracture mode of additively manufactured carbon fiber and glass fiber reinforced thermoplastics", Material and Design, vol. 137, pp. 79-89, 2018.

[9] P. Bedi, R. Singh and I. Ahuja, "Effect of SiC/Al2O3 particle size reinforcement in recycled LDPE matrix on mechanical properties of FDM feed stock filament", Virtual and Physical Prototyping, vol. 13, no. 4, pp. 246-254, 2018.

[10] B. Brenken, E. Barocio, A. Favaloro, V. Kunc and R. B. Pipes, "Fused filament fabrication of fiber-reinforced polymers: A review", Additive Manufacturing, vol. 21, pp. 1-16, 2018.

[11] A. Boschetto and L. Bottini, "Accuracy prediction in fused deposition modeling", International Journal of Manufacturing Technologies, vol. 73, no. 5-8, pp. 913-928, 2014.

[12] M. Taufik and P. Jain, "A study of build edge profile for prediction of surface roughness in fused deposition modeling", Journal of Manufacturing Science and Engineering, vol. 138, no. 6, p. 061002, 2016.

[13] D. Ahn, J.-H. Kweon, S. Kwon, J. Song and S. Lee, "Representation of surface roughness in fused deposition modeling", Journal of Materials Processing Technology, vol. 209, no. 15-16, pp. 5593-5600, 2009.

[14] A. Boschetto, V. Giordano and F. Veniali, "Modelling micro geometrical profiles in fused deposition process", The International Journal of Advanced Manufacturing Technology, vol. 61, no. 9-12, pp. 945-956, 2012.

[15] J. Rodriguez, J. Thomas and J. Renaud, "Characterization of the mesostructure of fused-deposition acrylonitrile-butadienestyrene materials", Rapid Prototyping Journal, vol. 6, no. 3, pp. 175-186, 2000.

[16] C. Bellehumeur, L. Li, Q. Sun and P. Gu, "Modeling of Bond Formation Between Polymer Filaments in the Fused Deposition Modeling Process", Journal of Manufacturing Engineering, vol. 6, no. 2, pp. 170-178, 2004.

[17] H. Li, T. Wang and Z. Yu, "The Quantitative Research of Interaction between Key Parameters and the Effects on Mechanical Property in FDM", Advances in Materials Science and Engineering, Article ID 9152954, 2017.

[18] S. Costa, F. M. Duarte and J. A. Covas, "Thermal conditions affecting heat transfer in FDM/FFE: a contribution towards the numerical modelling of the process", Virtual and Physical Prototyping, vol. 10, no. 1, pp. 35-46, 2015.

[19] S. Costa, F. Duarte and J. Covas, "Estimation of filament temperature and adhesion development infused deposition techniques", Journal of Materials Processing Technology, vol. 245, pp. 167-179, 2017.

[20] L. Li, Q. Sun, C. Bellehumeur and P. Gu, "Composite Modeling and Analysis for Fabrication of FDM Prototypes with Locally Controlled Properties", Journal of Manufacturing Processes, vol. 4, no. 2, pp. 129-141, 2002.

[21] O. A. Mohamed, S. H. Masood and J. L. Bhowmik, "Optimization of fused deposition modeling process parameters: a review of current research and future prospects", Advance Manufacturing, vol. 3, no. 1, pp. 42-53, 2015. 
[22] A. D’Amico, A. Debaie and A. M. Peterson, "Effect of layer thickness on irreversible thermal expansion and interlayer strength in fused deposition modeling", Rapid Prototyping Journal, vol. 23, no. 5, pp. 943-953, 2017.

[23] J. Chacón, M. Caminero, E. García-Plaza and P. Núñez, "Additive manufacturing of PLA structures using fused deposition modelling: Effect of process parameters on mechanical properties and their optimal selection", Materials and Design, vol. 124, pp. 143-157, 2017.

[24] J. Hesamodin, S. Masood and W. Song, "Dynamic Response of FDM Made ABS Parts in Different Part Orientations", Advanced Materials Research, vol. 748, pp. 291-294, 2013.

[25] F. Rayegani and G. C. Onwubolu, "Fused deposition modelling (FDM) process parameter prediction and optimization using group method for data handling (GMDH) and differential evolution (DE)", The International Journal of Advanced Manufacturing Technology, vol. 73, no. 1-4, pp. 509-519, 2014.

[26] X. Zhou, S.-J. Hsieh and C.-C. Ting, "Modelling and estimation of tensile behaviour of polylactic acid parts manufactured by fused deposition modelling using finite element analysis and knowledge-based library", Virtual and Physical Prototyping, vol. 13, no. 3, pp. 177-190, 2018.

[27] R. Anithaa, S. Arunachalam and P. Radhakrishnan, "Critical parameters influencing the quality of prototypes in fused deposition modelling", Journal of Materials Processing Technology, vol. 118, no. 1-3, pp. 385-388, 2001.

[28] K. Thrimurthulu, P. M. Pandey and N. V. Reddy, "Optimum part deposition orientation in fused deposition modeling", International Journal of Machine Tools \& Manufacture, vol. 44, no. 6, pp. 585-594, 2004.

[29] M. Jabbari, I. Baran, S. Mohanty, R. Comminal, M. R. Sonne, M. W. Nielsen, J. Spangenberg and J. H. Hattel, "Multiphysics modelling of manufacturing processes: A review", Advances in Mechanical Engineering, vol. 10, no. 5, pp. 1-31, 2018.

[30] M. Jabbari, J. Spangenberg and J. H. Hattel, "Particle migration using local variation of the viscosity (LVOV) model in tape casting of ceramics", Chemical Engineering Research and Design, vol. 109, pp. 226-233, 2016.

[31] M. Jabbari, J. Spangenberg and J. H. Hattel, "Interface Behavior in Functionally Graded Ceramics for the Magnetic Refrigeration: Numerical Modeling", Applied Mechanics and Materials, vol. 325-326, pp. 1362-1367, 2013.

[32] E. Hovad, J. Spangenberg, P. Larsen, J. H. Walther, J. Thorborg and J. H. Hattel, "Simulating the DISAMATIC process using the Discrete Element Method - a dynamical study of granular flow", Powder Technology, vol. 303, pp. 228-240, 2016.

[33] E. Hovad, P. Larsen, J. Spangenberg, J. Walther, J. Thorborg and J. H. Hattel, "Cavity prediction in sand mould production applying the DISAMATIC process", Powder Technology, vol. 321, pp. 204-217, 2017.

[34] J. Zhang, X. Z. Wang, W. W. Yu and Y. H. Deng, "Numerical investigation of the influence of process conditions on the temperature variation in fused deposition modeling", Materials \& Design, vol. 130, pp. 59-68, 2017.

[35] Y. Zhang and V. Shapiro, "Linear-Time Thermal Simulation of As-Manufactured Fused Deposition Modeling Components", Journal of Manufacturing Science and Engineering, vol. 140, no. 7, pp. 071002-1:11, 2018.

[36] C. Kousiatza, N. Chatzidai and D. Karalekas, "Temperature Mapping of 3D Printed Polymer Plates: Experimental and Numerical Study", Sensors, vol. 17, no. 3, 2017.

[37] A. D'Amico and A. M. Peterson, "An adaptable FEA simulation of material extrusion additive manufacturing heat transfer in 3D", Additive Manufacturing, vol. 21, pp. 422-430, 2018.

[38] Y. Zhang and Y. K. Chou, "Three-dimensional finite element analysis simulations of the fused deposition modelling process", Journal of Engineering Manufacture, vol. 220, no. 10, pp. 1663-1671, 2006.

[39] X. Zhou, S.-J. Hsieh and Y. Sun, "Experimental and numerical investigation of the thermal behaviour of polylactic acid during the fused deposition process", Virtual and Physical Prototyping, vol. 12, no. 3, pp. 221-233, 2017.

[40] M. R. Talagani, S. DorMohammadi, R. Dutton, C. Godines, H. Baid, F. Abdi, V. Kunc, B. Compton, S. Simunovic, C. Duty, L. Love, B. Post and C. Blue, "Numerical Simulation of Big Area Additive Manufacturing (3D Printing) of a Full Size Car", SAMPE Journal, vol. 51, no. 4, pp. 27-36, 2015.

[41] A. Favaloro, B. Brenken, E. Barocio and R. B. Pipes, "Simulation of polymeric composites additive manufacturing in Abaqus", in Science in the Age of Experience, Chicago, IL, 2017.

[42] B. Brenken, A. Favaloro, E. Barocio and R. B. Pipes, "Simulation of semi-crystalline composite tooling made by extrusion deposition additive manufacturing", in SAMPE Conference Proceedings, Seattle, WA, 2017. 
[43] A. Bellini, A Comprehensive Experimental, Analytical and Computational Study of Material Behavior, Fabrication Process and Equipment Design, Ph.D. Thesis, Drexel University, 2002.

[44] A. Bellini, S. Guceri and M. Bertoldi, "Liquefier Dynamics in Fused Deposition", Journal of Manufacturing Science and Engineering, vol. 126, pp. 237-246, 2004.

[45] H. S. Ramanath, C. K. Chua, K. F. Leong and K. D. Shah, "Melt flow behaviour of poly-e-caprolactone in fused deposition modelling", Journal of Material Science: Materials in Medicine, vol. 19, no. 7, p. 2541-2550, 2008.

[46] M. Nikzad, S. H. Masood, I. Sbarski and A. Groth, "A Study of Melt Flow Analysis of an ABS-Iron Composite in Fused Deposition Modelling Process", Tsinghua Science and Technology, vol. 14, no. S1, pp. 29-37, 2009.

[47] S. Dabiri, S. Schmid and G. Tryggvason, "Fully Resolved Numerical Simulations of Fused Deposition Modeling", in Proceedings of the ASME 2014 International Manufacturing Science and Engineering Conference, Detroit, Michigan, USA, 2014.

[48] H. Xia, J. Lu, S. Dabiri and G. Tryggvason, "Fully Resolved Numerical Simulation of Fused Deposition Modeling. Part I - Fluid Flow", Rapid Prototyping Journal, vol. 24, no. 2, pp. 463-476, 2018.

[49] H. Xia, J. Lu and G. Tryggvason, "Fully Resolved Numerical Simulations of Fused Deposition Modeling. Part II. Solidification, Residual Stress, and Modeling of the Nozzle", arXiv preprint 1711.07094, 2017.

[50] J. Du, Z. Wei, X. Wang, J. Wang and Z. Chen, "An improved fused deposition modeling process for forming large-size thinwalled parts", Journal of Materials Processing Technology, vol. 234, no. August 2016, pp. 332-341, 2016.

[51] B. Heller, D. E. Smith and D. Jack, "Effects of extrudate swell and nozzle geometry on fiber orientation in Fused Filament Fabrication nozzle flow", Additive Manufacturing, vol. 12, pp. 252-264, 2016.

[52] C. Mcllroy and P. D. Olmsted, "Deformation of an amorphous polymer during the fused-filament-fabrication method for additive manufacturing", Journal of Rheology, vol. 61, no. 2, pp. 379-397, 2017.

[53] R. Comminal, J. Spangenberg and J. H. Hattel, "Numerical Simulations of Planar Extrusion and Fused Filament Fabrication of Non-Newtonian Fluids", Annual Transactions of The Nordic Rheology Society, vol. 25, pp. 263-270, 2017.

[54] J. Liu, K. L. Anderson and N. Sridhar, "Direct Simulation of Polymer Fused Depostion Modeling (FDM) - An implementation of the Multi-Phase Viscoelastic Solver in OpenFOAM", International Journal of Computational Methods, vol. 15, no. 1, pp. 1844002:1-19, 2018.

[55] R. Comminal, M. P. Serdeczny, D. B. Pedersen and J. Spangenberg, "Numerical modeling of the strand deposition flow in extrusion-based additive manufacturing", Additive Manufacturing, vol. 20, pp. 68-76, 2018.

[56] M. P. Serdeczny, R. Comminal, D. B. Pedersen and J. Spangenberg, "Numerical Study of the Impact of Shear Thinning Behaviour on the Strand Deposition Flow in the Extrusion-based Additive Manufacturing", in Euspen's 18th International Conference and Exhibition, Venice, IT, 2018.

[57] BQ, "GitHub - BQ/Hephestos 2 Repository", [Online]. Available: https://github.com/bq/hephestos-2.

[58] G. P. Greeff and M. Schilling, "Closed loop control of slippage during filament transport in molten material extrusion", Additive Manufacturing, vol. 14, pp. 31-38, 2017.

[59] "ANSYS ${ }^{\circledR}$ FLUENT R18.2, ANSYS FLUENT Theory Guide, @ ANSYS, Inc", 2017.

[60] C. W. Hirt and B. D. Nichols, "Volume of fluid (VOF) method for the dynamics of free boundaries", Journal of Computational Physics, vol. 39, no. 1, pp. 201-225, 1981.

[61] M. Sussman and E. G. Puckett, "A Coupled Level Set and Volume-of-Fluid Method for Computing 3D and Axisymmetric Incompressible Two-Phase Flows", Journal of Computational Physics, vol. 162, pp. 301-337, 2000.

[62] R. Comminal, J. Spangenberg and J. Hattel, "Cellwise conservative unsplit advection for the volume of fluid method", Journal of Computational Physics, vol. 283, pp. 582-608, 2015.

[63] S. Muzaferija, M. Peric, P. Sames and T. Schellin, "A Two-Fluid Navier-Stokes Solver to Simulate Water Entry", in 22nd Symposium on Naval Hydrodynamics, 1999. 